\title{
Culture and Second Language Aquisition: Arabic Language as a Model
}

\author{
Tawfiq Omar, (MA)
}

The University of Jordan, Jordan

\section{doi: 10.19044/esj.2016.v13n2p159 URL:http://dx.doi.org/10.19044/esj.2016.v13n2p159}

\begin{abstract}
This study is an examination of the role and impact of culture and culture literacy on second language acquisition. It will adopt the qualitative approach, using multiple case study design, interviews and observation, to generate somehow rich descriptions of the role of culture on second language acquisition. The study used a sample of the international students studying Arabic at the Language Center at The University of Jordan.

Multiple methods of data collection over a period of four months were used. The researcher collected data through in-depth interviews and nonparticipant observations.

The purpose of this study is to examine to which extent culture, with all its elements and components, helps learners of Arabic boost their language and linguistic skills. Living an Arabic culture (the Jordanian culture as an example), enriches learners' language skills and accelerates their progress due to the direct interaction with the people and their native culture. This will enable them to interact, using the language they acquire, in complex cultural situations raising their self-confidence and encouraging them to use the language more effectively gaining new ways of thinking and widening their linguistic and cultural competence.
\end{abstract}

Keywords: Culture, Language acquisition, Arabic as a second language

\section{Introduction}

Culture plays an important role in boosting the linguistic abilities of learners of a second language. This applies to learners of Arabic as a second language. Living and experiencing an Arabic culture has a substantial influence on how language is acquired and used. It permits the development of the ability to interpret others (Hager, 2011). Each culture has its own characteristics and shaping factors that develop over a span of hundreds or thousands of years. 
Since aims are the first and most important consideration in any teaching environment, the main objective of second/foreign language education should focus on the communicative proficiency and intercultural competence of the learner. "In intercultural communication, how someone expresses what that person means and how others interpret a message, is extremely important” (Hager, 2011:103). Learning while living in a native culture will help the learner receive, analyze and produce. The production of language in its many linguistic forms and skills is something that can be earned and developed and it is the ultimate objective. This production of language is mediated and fostered by culture; by its people contributing to its richness and diversity.

Intercultural communication helps shaping the culture-language connection which is a combination of personal and linguistic experiences intertwined. People, places, experiences, history and traditions are all shaping factors of any culture. Exposing learners of language to culture with all its elements will definitely have an impact not only on their personal lives but also on their language as well.

The assumption here is that culture affects language. In most cases in a positive way that pushes the leaner further and boosts his/her language acquisition because of many factors that can only be found the native culture of the language. The amount of role culture contributes to language is huge when language is studied in a culture experiencing all of its aspects because speaking a language is also about behaving it. Culture becomes like the soul and spirit of language that gives it its life. This paper introduces the concepts of language and culture then examines the connection and relation between the two.

\section{The data}

To examine this further, some learners of Arabic at the Language Center at The University of Jordan have been interviewed and asked about the role culture plays in their language acquisition. More than 1000 students form diverse backgrounds and cultures study Arabic at the Language Center every year. These students chose to study Arabic in Jordan because of many reasons. Learning language within a cultural context was one of their main reasons they decided to study Arabic in Jordan or in an Arab country. Many arrive to the Jordan with a widely set of values, identities and intentions. The identity and knowledge of their first culture in addition to pre-assumptions about the new culture, shape and influence how they view and survive that new culture. 


\section{The data analysis}

This study adopted a multimethod approach, employing a range of quantitative methods, including documentary analysis, observation and analysis of a series of interviews. To observe the effect of culture on language, conversation analytic tools were employed to measure that effect.

The questions asked were prepared to examine if culture really had an effect of those students. The questions were reviewed and evaluated by experts in teaching Arabic to Speakers of Other languages. This paper is an analysis of their responses and a projection of how culture affects language.

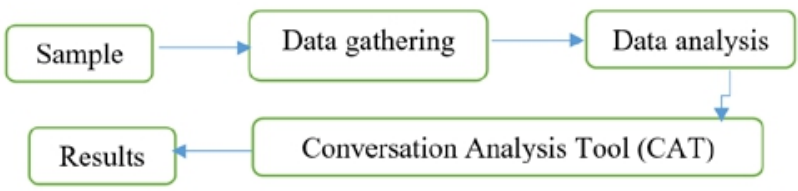

\section{Language and culture}

The relationship between culture and language is a complex one. The two concepts of language and culture have been given much attention from scholars over time and continue to be discussed by social scientists, educators and students all over the world. Culture "encompasses objects and symbols, the meanings given to those objects and symbols, and the norms, values, and beliefs that set the cultural boundaries recognized in the community and constructed by it” (Reeves-Ellington, R. H., \& Yammarino, 2010). Culture is also about shared values, traditions, the way people think, customs and histories. Culture shape the way a person thinks, behaves and views the world. A shared cultural heritage bonds the members of the group together and creates a sense of belonging through community acceptance (Hager, 2011). That community acceptance is crucial in language adaptation. All the prepared concepts and ways of understanding what culture is like or what is it in reality can never be examined unless a person lives that culture.

Culture and language affect each other. Culture broadens the awareness in learners' linguistic needs and realities. The loss of language on the other hand means the loss of culture (Hager, 2011). It is through culture that learners of any language know more about that culture's identity and history and as a result helps in shaping their language identity as well. Understanding cultural diversity is a key word in living and surviving it.

I started with Siyu Liu, a student from China in level 6, who said that her "love for Arabic was only complete when she came to Jordan" Only then all the things she imagined about culture came to reality. "My understanding of how language work became obvious after indulging myself in the country and culture.” (Liu, Personal communication, November 26, 2016).

Culture and language share two important components: identity and attitude. Each has its own unique identity which in turn affects the other. One 
might have a cultural identity and a different/similar linguistic identity. The two identities or one of them may change with the course of time affecting the attitude or the way a learner of a language approaches or perceives culture or language. Aria Weiss from the Netherlands thinks that the Jordanian culture has helped her greatly in shaping her linguistic identity and attitude. To her, culture is not only the place but also extends to include thoughts, ideas and way of life. Many aspects of culture are apparent in how people use their language. Generosity and welcoming visitors for example are reflected in language making it easier for learners of Arabic to easily understand them and live them first hand. The use of words is interesting. Just for welcome, Jordanians have so many expressions as well as for loving remarks. These are all part of their language and that is why you see it in their language so much (Weiss, Personal communication, December 1, 2016).

This view is also shared by Victoria Jackson, a student from the United States of America who came to study Arabic Jordan for the first time. She thinks that culture gave her the opportunity to experience language and learn it the native speakers do. It is the different situation the students find themselves in that force them to use the language. All aspects of language become like supporting base. The use of the dialect is extremely important. By learning the Jordanian dialect and using it with Jordanians, she has gained access to hidden aspects of culture which increased her personal and language confidence. The trips she had participated in to Jordan's cultural and historical places connected her with language even more. It has become a passion for her learn Arabic more and a $\mathrm{t}$ a faster pace. Nevertheless, she admits that she had troubles at the beginning when she came to Jordan. She came "unprepared" as she describes herself. She was just a total beginner of Arabic and illiterate in culture as well. "I felt like a stranger at the beginning because I did not seem to fit in and at times I was about to abandon the whole endeavor and go home.” It was by having few new Jordanian friends who invited her to their homes and took her to see places that she managed to pull herself together and regain her self-confidence. "the nice people I have met actually helped a lot but it was the newly discovered aspects of the country and the culture that helped fall in love with Arabic. Those things were a mystery to me one day." (Victoria Jackson, Personal communication, December 4, 2016).

R. Milrood (2012) specifies the content of culture by subdividing it into five components: culture elements, culture manifestations, culture indicators, culture facts, and culture dimensions. This structure is built on the principle and is graphically presented in the shape of a pyramid, at its foundation we find culture dimensions, whereas its peak is made up of culture elements. The two visible factors that we can see are culture elements 
and culture manifestations. "The distinguishing feature between these two groups is that the "elements" can be learnt from various sources, not necessarily involving direct contact with the target language environment, whereas culture manifestations are the observations of the learner, as well as their cultural experiences, made in contact with native speakers.” (Hackett 2016:55).

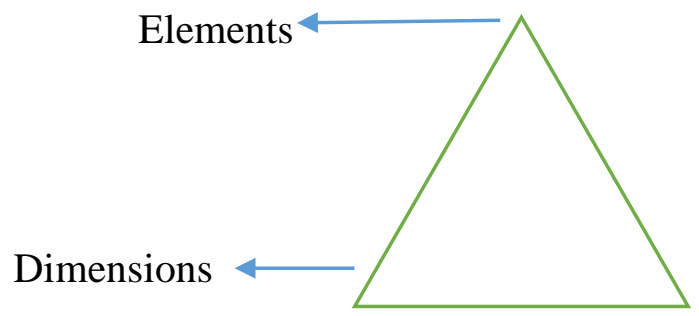

Learning a language in its native culture puts emphasis on participation and interaction among the peoples of the community. It is something that goes beyond the textbook with the purpose of stimulating learners to add cultural components to their linguistic repertoire and driving them to produce optimal performance. It is in the culture that a person gets a better understanding of the language and its motives. Janosch Lipowsky, a French student in level seven says that Jordanians think that he a native speaker of Arabic. "The way I talk, the way I approach people and how I behave in a community other my native all have changed. When I speak Arabic, I speak it with flawless accent especially Spoken Arabic." (Lipowsky, Personal communication, December 14, 2016).

Lipowsky lived in Lebanon for one year where he studied Arabic while living with a Lebanese family. He was not only exposed to one variety of Arabic culture but two. That seemed to give him more confidence when around others and when using the language. It also provided him with the exciting feeling of blending in with the target society and culture. Kasper (1997) emphasizes the role of linguistic etiquette in cultures claiming it to be a shaper of both communicative contexts as well as human relationships. Though linguistic norms differ between cultures, demonstrating respect towards others is an important function of language. "I felt more appreciated and people started inviting me to their homes and they have become more open with me even in discussing things and topics which are concerned taboos to non-native speakers of the language or those who are non-native of the culture. I in return was able to combine two cultures to produce a third improved one if I may say so and I have to admit that using language and culture correctly helped me tremendously." (Lipowsky, Personal communication, December 14, 2016). 
This will lead to talk about Coupland's Communication Accommodation Theory (CAT). According to accommodation theory, the three key goals underlying speech accommodation are evoking the addressee's social approval, promoting communicative efficiency between interlocutors, and maintaining a positive social identity. If speakers come from different language and sociocultural backgrounds, accommodation processes can have a far more significant role in facilitating understanding than they would in interactions between speakers from similar backgrounds. In this sense, accommodation theory lends itself well to analyses of intercultural communication (Beebe \& Giles, 1984).

An important question arises and, indeed, imposes itself. Is culture a pre-requisite to language or is it just the other round? Linguistic and cultural competency is a good starting point for any language education approach. Evoking learners' positive cultural identity is important in boosting their language acquisition. If language is set to reflect the perceptions of those who speak it, then the conceptions and thoughts of those who employ that language would also be affected by it. Culture equals identity. Lipowsky thinks that just learning a language seems to be superficial. It is complemented by culture since at the end of the day the language that learn is the language that you practice (Lipowsky, Personal communication, December 14, 2016). One of the most influential reasons that made students come to learn Arabic in Jordan was their desire to learn language in context where everything they learn is reflected in real life. Their textbooks cover some cultural aspects but not enough to compensate learning a language in its native environment.

Students are eager and keen to know more about traditions and how people of the native language live in their own culture. To many students in the west that is a mystery and trying to connect the language with culture without living it might from an obstacle preventing them from real appreciation of the language. This will lead many to think of that language and Arabic for example, difficult to learn. That is why many decide to participate in study abroad programs to break that barrier between language and the context in which it is spoken. Communication seems be the main purpose why most of the students decided to come to the native culture of Arabic. When asked about the most language skill improved, they all answered "speaking”. Speaking is their first tool to communicate with people of the culture and to get to know more about it and them. Naturally, listening was the second skill improved. It is that personal experience that makes all the difference. Being improved, the speaking and listening skills equipped students with self-confidence. Their hunger for more "knowledge" increased. Their interest in other disciplines in the language also increased. The 
transition from just studying the language to giving it life with a taste of their own also increased.

It is also critical to understand the motives behind learning a language or understanding culture. Tamara Haddad, is a heritage student from Chile. She came to Jordan to study Arabic because as she wants to know more about her ancestors' heritage and culture personally. "I have lived in a house that appreciates pride in history and culture. I know little Spoken Arabic because my parents sometimes communicate with me in Arabic but I have never been taught Modern Standard Arabic unfortunately. I felt that by coming here I would know more about my family's heritage and culture and live the experience they have lived one day." She could not find dedicated programs in Jordan that focus on the theoretical and the applicable sides of culture so she to come to Jordan to study Arabic for two semesters hoping that she could find more about culture while doing so. (Haddad, Personal communication, December 1, 2016).

\section{The outcome}

From observation and interviews, it was noticed that students who have been exposed to more than one culture, heritage students or students coming from certain ethnic backgrounds adapt more to all varieties and aspects of culture and they become more flexible in accepting differences among cultures and shortens the period required to learn a language. Culture literacy then is extremely important in language acquisition. In Swahili, words related to crimes, cases in courts of law and materialistic needs are derived from western and European cultures while words related to morals and social values came from the Arabic culture. The acceptance of culture and its role for someone coming from Somalia then would be faster and the results would be quicker as well. In Tamara's case where language to her was merely a vehicle to understanding culture better changed with time. Living culture has provided her with a deeper insight and greater appreciation of the Language. It also helped her adapt and communicate well with people in the community. I have noticed that mission of those students who lived in an Arab culture before and have an idea about how some or part of the system works or those who had previous knowledge about the target culture was much easier and their grasp of the language was smoother and faster. Both language and culture complement each other. On the other hand, students who had no previous knowledge of the culture had some troubles at the beginning and then some managed to adapt and some did not. their language acquisition hindered and was not as fast as those who felt more comfortable in the culture.

A survey carried out by the "Jerusalem Institute for Israel Studies," in 2012 directed towards the Jewish population (educators and students) 
reported that $60 \%$ of the respondents favor the inclusion of Arab culture in the Hebrew schools while 69\% of them support the Arabic language education in those schools. These results supported the latest survey carried out by the Central Bureau of Statistics in 2011 which reported that 68\% of respondents believe it is "significant" or "very important" to study Arabic culture and for Arabic to be a compulsory subject in schools

This paper is humble attempt to prove that culture boosts learners' language skills and the ability to put them to practice and that their use of the language goes beyond just knowing the its skills to putting them in context where they can relate things in real time instead of visual expectation that might change the course of their language learning.

It is strongly recommended that further dedicated and detailed investigation to the role of culture shall be conducted taking in mind more variables that might affect the progress of students during the course of their study of language in a native environment.

\section{References:}

1. $60 \%$ favor the education of Arab culture in Jewish schools, 2014. Derived from: http://mfa.gov.il/MFAAR/IsraelExperience/ArtCultureAndSport/Pag es/Arabic-studies.aspx

2. Beebe, L., \& Giles, H. (1984). Speech accommodation theories: A discussion in terms of second language acquisition. International Journal of the Sociology of Language, 46, 5-32.

3. Hackett-Jones A.V. (2016). Russian Linguistic Bulletin, №3 (7), 141143. http://dx.doi.org/10.18454/RULB.7.08

4. Hager, M. (2011). Culture, Psychology, and Language Learning. Oxford: Peter Lang AG

5. Kasper, G. (1997). Linguistic Etiquette. The handbook of sociolinguistics (pp. 374-385). United Kingdom: Blackwell Publishers.

6. Milrood, R. P. (2012). Teaching culture and culture language teaching. Herald of Tomsk state University. Series: Humanitarian Sciences. No. 4 (108). Tambov: Publishing house TSU.

7. Reeves-Ellington, R. H., \& Yammarino, F. J. (2010). What Is Culture? : Generating and Applying Cultural Knowledge. Lewiston: Edwin Mellen Press.

8. Taylor, M. (1992), The Language Experience Approach and Adult Learners. National Center for ESL Literacy Education Retrieved from: http://www.cal.org/caela/esl_resources/digests/LEA.html 